\title{
Travel Delay and Modal Split Analysis - A Case Study
}

\author{
H.S.Sathish ${ }^{1}$, Dr. H.S.Jagadeesh ${ }^{2}$, Skanda Kumar ${ }^{3}$ \\ ${ }^{1,2}$ (Department of Civil Engineering, BMS College of Engineering, Basavanagudi, Bangalore, India \\ ${ }_{3}^{3}$ (Former Postgraduate Student, Department of Civil Engineering, BMS College of Engineering, Basavanagudi, \\ Bangalore, India
}

\begin{abstract}
Journey time and delay study is used to evaluate the quality of service, the travel time and study can also be used to evaluate the quality of traffic movement along the route and to determine the location types and extent of traffic delays. Components of delay are boarding and alighting, issue of tickets, other causes and distance between each stops. This study investigates the total journey time required to travel along the stretch and the influence the delays. The route starts from Kempegowda Bus Station to Yelahanka Satellite Station of Bangalore City. The length of the stretch is $16.5 \mathrm{~km}$. Modal split analysis has been done for this stretch. This stretch has elevated highway connecting to Bangalore International Airport and the extension of Metro Transit. stretch. From the regression analysis of total journey time it is affected by delay due to boarding and alighting moderately, Delay due to issue of tickets affects the journey time to a higher extent. Some of the delay factors affecting significantly the journey time are evident from F-test at 10 percent level of confidence. Along this stretch work trips are more prevalent as indicated by $O-D$ study. Modal shift analysis indicates about 70 percent of commuters are ready to shift from current system to Metro Rail System. Metro Rail System carries maximum number of trips compared to private mode. Hence Metro is a highly viable choice of mode for Bangalore Metropolitan City.
\end{abstract}

Keywords: Delay, Journey time, Modal Choice, Regression Analysis

\section{Introduction}

Transportation is a vital component of economic development, social progress and quality of life of urban transportation. The number of trips made by different modes within and outside the area depends on its accessibility to the required services and facilities.

The choice of transport mode is probably one of the most important classic models in transport planning. This is because of the key role played by public transport in policy making. Public transport modes make use of road space more efficiently than private transport. Also they have more social benefits like if more people begin to use public transport, there will be less congestion on the roads and the accidents will be less. Again in public transport, we can travel with low cost. In addition, the fuel is used more efficiently. Main characteristics of public transport are that they will have some particular schedule, frequency etc.

On the other hand, private transport is highly flexible. It provides more comfortable and convenient travel. It has better accessibility also. The issue of mode choice, therefore, is probably the single most important element in transport planning and policy making. It affects the general efficiency with which we can travel in urban areas. It is important then to develop and use models which are sensitive to those travel attributes that influence individual choices of mode.

Modal split is the process of separating person's trips by the mode of travel. In general, modal split refers to the trips made by private car as opposed to public transport with respect to passenger modal split. Modal split continues to receive primary attention from investigators interested in urban transportation modeling, probably because completely acceptable models have yet to be developed and because the modal split problem is of the most concern while deciding among alternative transportation proposals. In recent years one of the most favored approaches to modal split has been to pose problem as one of general consumer choice and utilize logit analysis to solve it.

\subsection{Overview of Bangalore Transport in the study stretch Kempegowda Bus Station to Yelahanka Satellite Town}

The new International Airport is in Devanahalli, is in operation at $31 \mathrm{~km}$ North of Bangalore. Also, the construction of the 6-lane Bangalore-Devanahalli expressway is underway, and most parts are nearly completed. Bangalore is well connected to the rest of the country through the Indian Railways. The city is connected to Delhi, Mumbai, Chennai, Kolkata, and Hyderabad, as well as other major cities of India and Karnataka.

An intra-city rapid rail transport Yelahanka Satellite Town called the Namma Metro is being developed and is expected to completed by 2015.The metro once ready, will comprises of a $33 \mathrm{~km}$ elevated and underground rail network, with 32 stations in phase I and more being added in phase II. Auto rickshaws are 
popular form of public transport. Autos are metered and can accommodate up to three passengers. Taxi service within Bangalore is provided by several operators commonly referred as city taxis and can take in up to four passengers and are usually metered and relatively more expensive than auto-rickshaws.

Bangalore Metropolitan Transport Corporation (BMTC) operates a fleet of 5,350 BMTC public buses including Air conditioned Volvo, Pushpak, Big10 buses on all routes, servicing an average of 3,800,000 commuters. The main bus depots that BMTC maintains are the Kempegowda Bus Station, locally known as "Majestic", Shantinagar Bus Depot, and Shivajinagar Bus Depot (1).

\subsection{Importance of Public Transport}

Increase in the number of personal vehicles creates problems such as traffic congestion, increase in number of accidents, parking problems and environmental pollution. One of the effective measures to overcome the above problems and for fuel conservation is to patronize the public transport or mass transit Yelahanka Satellite Town.

In Bangalore city, it has been observed from the previous studies that the level of service for the automobiles on the city roads measured in terms of volume to capacity ratio has been declining during the past decade. Obviously, it is not possible to increase the roadway facilities such as carriageway width in proportion to the increases in traffic in the city. As the moving space occupied by bus to transport 50 persons is about $1 / 7$ th of that occupied by two-wheeler automobiles to transport the same number of persons, it will be advantageous in many ways if the public transport is made more effective and attractive.

\subsection{Growth of Bangalore Region}

The population of Bangalore has been growing rapidly since the decade of 1941-51 and by 1961 it had become the sixth largest city in the country. The city underwent extraordinary growth post 1971 and as per data of the 2001 census, the population of Bangalore stands at 5.69 million. In more recent times, following the expansion of jurisdiction of the Bangalore Mahanagara Palike (BMP) to constitute Bruhat Bangalore Mahanagara Palike (BBMP) in 2011, the estimated population is around 8 million as shown in Figure 1.1.

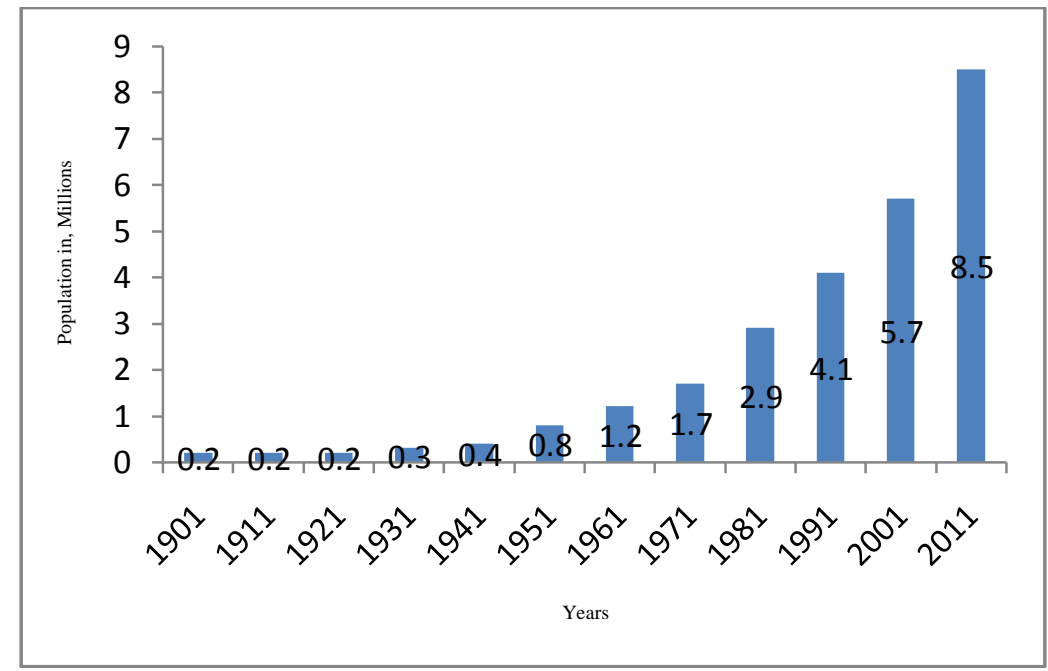

Figure 1.1: Bangalore population from 1901 to 2001

\subsection{Objectives of the study}

The main objectives of present study are:

i. To analyze the effect of components of delay to total journey time.

ii. To develop relationships between the components total delay like delays due to boarding and alighting, delays due to issue of tickets, delays due to other causes and distance between each stops.

iii. To develop Multi-linear Regression model for total journey time by stepwise regression method.

iv. To develop Utility function and Modal split.

\subsection{Study Area Details}

\section{Field SURVEY AND DATA COLLECTION}

The study road stretch selected for the present study is from Majestic Bus Station also known as the Kempegowda Bus Station (Kempegowda Bus Station) which is quite neatly organized and easily navigable to Yelahanka Satellite Town. The total stretch length was 16.5 kms from Kempegowda Bus Station to Yelahanka 
Satellite Station and $17.5 \mathrm{kms}$ from Yelahanka Satellite Station to Kempegowda Bus Station. Based on the characteristics of the study the Bus service 284-d was selected. Figure 1 shows the study area between Kempegowda Bus Station and Yelahanka Ssatelite Town. There are 10 major bus stops along the study area .

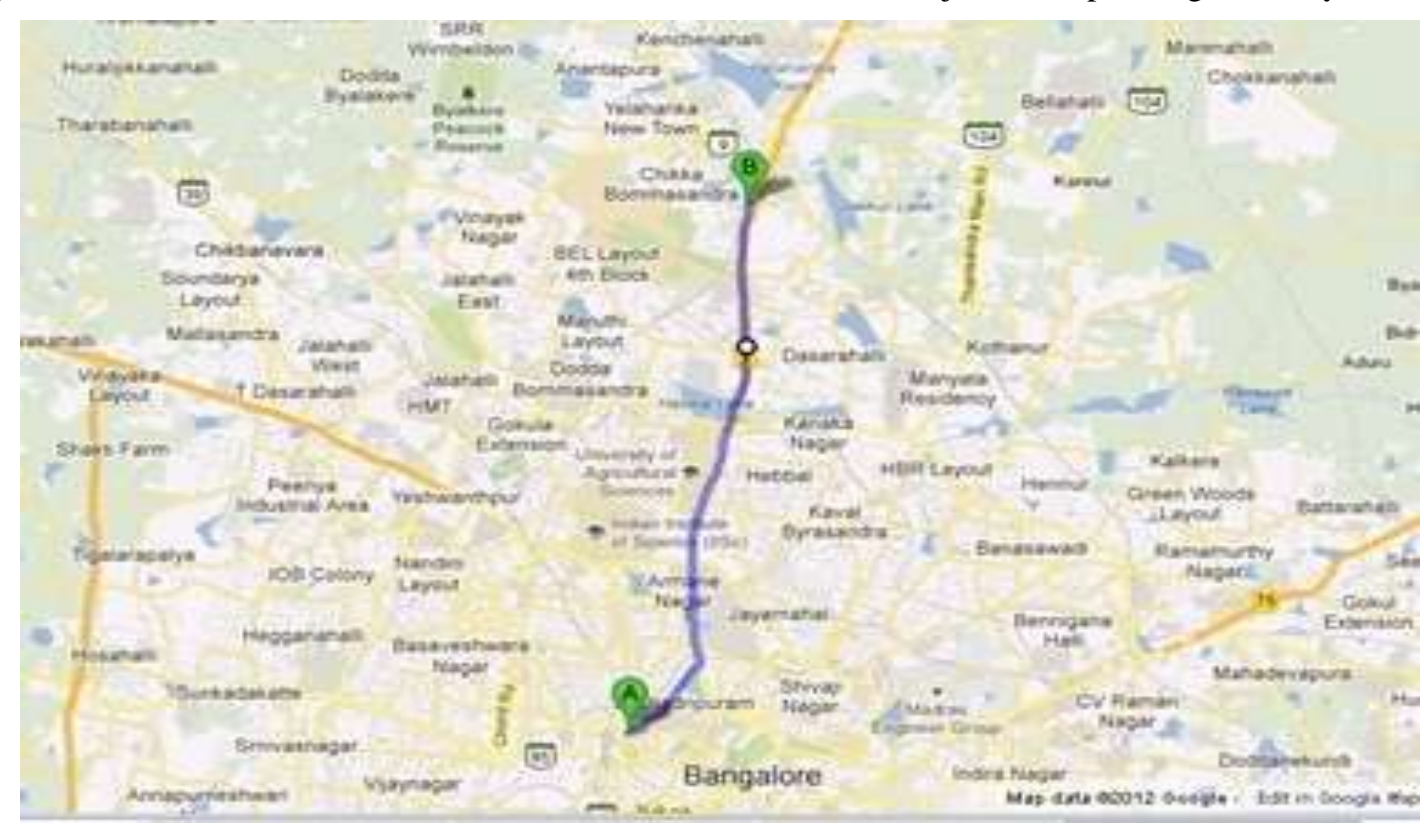

Figure 1: Map showing Study Area along Kempegowda Bus Station and Yelahanka Satelite Town

\subsection{Data Collection}

\subsubsection{In-Bus Survey}

The survey was conducted by in-bus for the route number $284 \mathrm{~d}$ for one week. The surveys were conducted from $8.00 \mathrm{am}$ to $8.00 \mathrm{pm}$, thus covering both peak and off-peak periods in both directions of travel. A total of 53 trips were covered. The following data were collected from In-Bus survey :

i). Stopped time at each bus stop with causes

ii). Other delays caused enroute with causes and duration.

iii). Time of reaching each of the pre-specified points along the route.

iv). Starting and ending time of the trip

\subsubsection{Travel Time Survey}

Car travel time survey was conducted in the study stretch . The enumerators were asked to note down the journey time between Kempegowda Bus Station to Yelahanka Satellite Station. Car travel time survey carried out during both peak and off-peak hours. An average journey time was then found out. Delay time due to fixed signal points and delays due to other causes (operational delays) were also noted down. Travel time cost by car was calculated.

\section{AnAlysis Of THE DATA}

The analysis has been carried out to assess the effect based on the opinion survey, journey time and modal split.

\subsection{Analysis of the Data}

3.1.1 The analysis of the data can be categorized into three parts:

i. Analysis of Journey Time and

ii. Analysis of Modal Split

\subsubsection{Analysis of the Journey Time:}

To determine the values of independent variables of the journey time model, the following Regression models have been generated by considering the total of each trip data as each individual observation. To start with regression analysis Delays due to Boarding/Alighting, Delays due to Issue of Tickets, Delays due to other causes, Distance between each stops were taken into consideration. The dependent variable Y, Journey time was fixed with different independent variables.

The following models have been calibrated: 
1. Journey time to Delays due to Boarding/Alighting Model:

$$
\mathrm{Y}=\mathrm{f}\left(\mathrm{X}_{1}\right)
$$

2. Journey time to Delays due to Issue of Tickets (number of passengers serviced) Model:

$$
\mathrm{Y}=\mathrm{f}\left(\mathrm{X}_{2}\right)
$$

3. Journey time to Delays due to other causes Model:

$$
\mathrm{Y}=\mathrm{f}\left(\mathrm{X}_{3}\right)
$$

4. Journey time to Distance between each stops Model:

$$
\mathrm{Y}=\mathrm{f}\left(\mathrm{X}_{4}\right)
$$

Where,$Y=$ Journey time, in Seconds, $X_{1}=$ Delays due to Boarding/Alighting, in Seconds, $X_{2}=$ Delays due to Issue of Tickets, in Seconds , $\mathrm{X}_{3}=$ Delays due to other causes, in Seconds, $\mathrm{X}_{4}=$ Distance between each stops, in m.

Table 1: Pearson's Correlation Matrix for Independent variables

\begin{tabular}{|c|c|c|c|c|}
\hline Variable & $\mathrm{X}_{1}$ & $\mathrm{X}_{2}$ & $\mathrm{X}_{3}$ & $\mathrm{X}_{4}$ \\
\hline $\mathbf{X}_{\mathbf{1}}$ & $\mathbf{1 . 0 0 0}$ & 0.4863 & -0.0115 & 0.6484 \\
& $\mathbf{P}=\mathbf{0 . 0 0}$ & $\mathrm{P}=0.154$ & $\mathrm{P}=0.975$ & $\mathrm{P}=0.043$ \\
\hline $\mathbf{X}_{\mathbf{2}}$ & $\mathbf{0 . 4 8 6 3}$ & $\mathbf{1 . 0 0 0}$ & 0.6274 & 0.8287 \\
& $\mathbf{P}=\mathbf{0 . 1 5 4}$ & $\mathbf{P}=\mathbf{0 . 0 0}$ & $\mathrm{P}=0.052$ & $\mathrm{P}=0.003$ \\
\hline $\mathbf{X}_{\mathbf{3}}$ & $\mathbf{- 0 . 0 1 1 5}$ & $\mathbf{0 . 6 2 7 4}$ & $\mathbf{1 . 0 0 0}$ & 0.4656 \\
& $\mathbf{P}=\mathbf{0 . 9 7 5}$ & $\mathbf{P}=\mathbf{0 . 0 5 2}$ & $\mathbf{P}=\mathbf{0 . 0 0}$ & $\mathrm{P}=0.175$ \\
\hline $\mathbf{X}_{\mathbf{4}}$ & $\mathbf{0 . 6 4 8 4}$ & $\mathbf{0 . 8 2 8 7}$ & $\mathbf{0 . 4 6 5 6}$ & $\mathbf{1 . 0 0 0}$ \\
& $\mathbf{P = \mathbf { 0 . 0 4 3 }}$ & $\mathbf{P}=\mathbf{0 . 0 0 3}$ & $\mathbf{P}=\mathbf{0 . 1 7 5}$ & $\mathbf{P}=\mathbf{0 . 0 0}$ \\
\hline
\end{tabular}

Table 1 indicates Pearson's correlation Matrix for Independent variables. From the table it can observed that Delays due to Boarding/Alighting, Delays due to Issue of Tickets, Distance between each stops shows predominantly positive correlation with one another. Following Table 2 shows the results of One-variable regression analysis.

Table 2: One variable Regression models:

\begin{tabular}{|l|c|c|c|c|c|c|}
\hline \multicolumn{1}{|c|}{ Model } & Equation & $\mathrm{R}^{2}$ & $\mathrm{~N}$ & $\mathrm{~F}_{(\mathrm{Cal})}$ & $\mathrm{F}_{(0.1)}$ & Remarks \\
\hline $\begin{array}{l}\text { Journey time to Delays due } \\
\text { to } \\
\text { Model }\end{array}$ & $\mathrm{Y}=118.8 \mathrm{x}-1438$ & 0.327 & 10 & 3.94 & 3.14 & Significant \\
\hline $\begin{array}{l}\text { Journey time to Delays due } \\
\text { to Issue of Tickets Model }\end{array}$ & $\mathrm{Y}=236.1 \mathrm{x}-1689$ & 0.697 & 10 & 3.15 & 3.14 & Significant \\
\hline $\begin{array}{l}\text { Journey time to Delays due } \\
\text { to other causes Model }\end{array}$ & $\mathrm{Y}=5.232 \mathrm{x}+1198$ & 0.275 & 10 & 3.03 & 3.14 & $\begin{array}{c}\text { Not } \\
\text { significant }\end{array}$ \\
\hline $\begin{array}{l}\text { Journey time to Distance } \\
\text { between each stops Model }\end{array}$ & $\mathrm{Y}=0.202 \mathrm{x}+35.79$ & 0.984 & 10 & 7.75 & 3.14 & Significant \\
\hline
\end{tabular}

Models journey time to delays due to boarding and alighting, journey time to delays due to issue of tickets, journey time to distance between each stops are showing significance at 10 percent level of confidence of F-test. The various relationships are shown in Fig 2 to Fig 6.

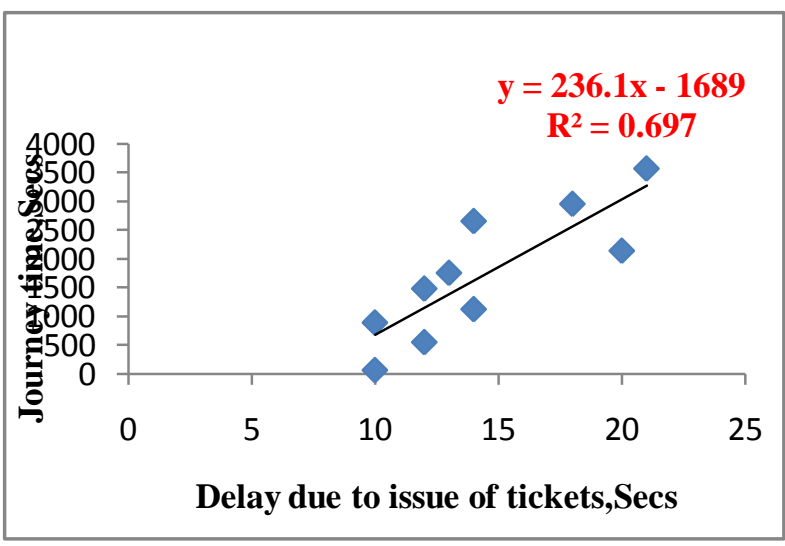

Figure 2: Plot of Journey Time and Delays due due to Boarding and Alighting in seconds

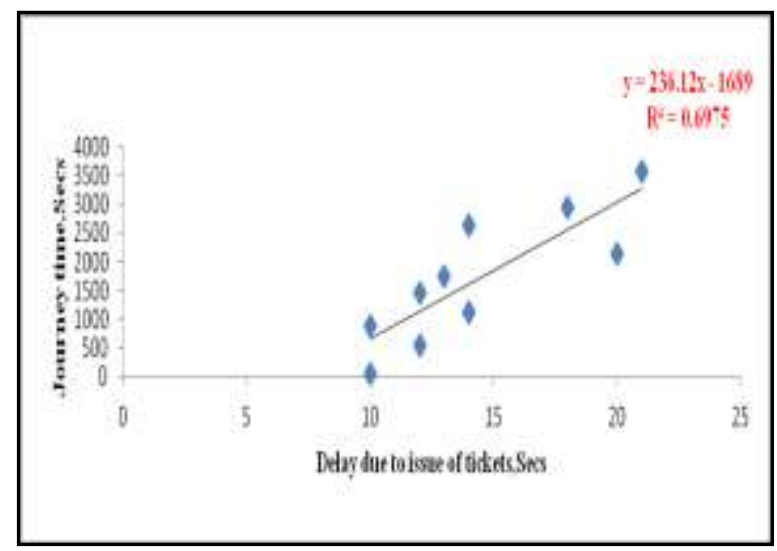

Figure 3: Plot of Journey Time and Delays to issue of Tickets in seconds 


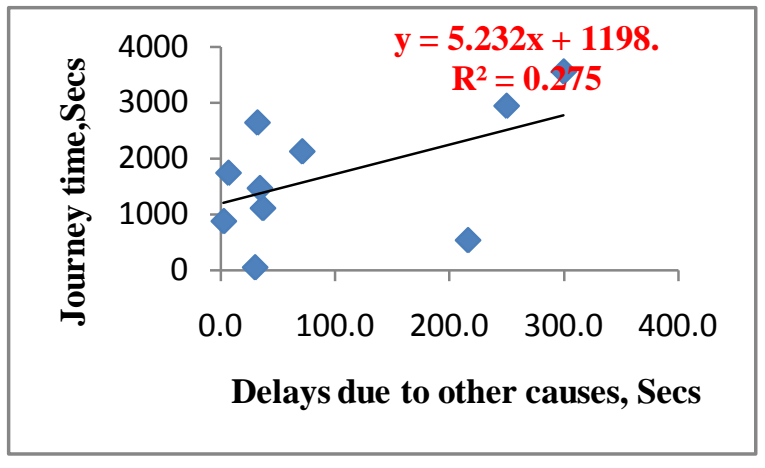

Figure 4 : Plot of Journey time and delay due to Distance Other Causes in seconds

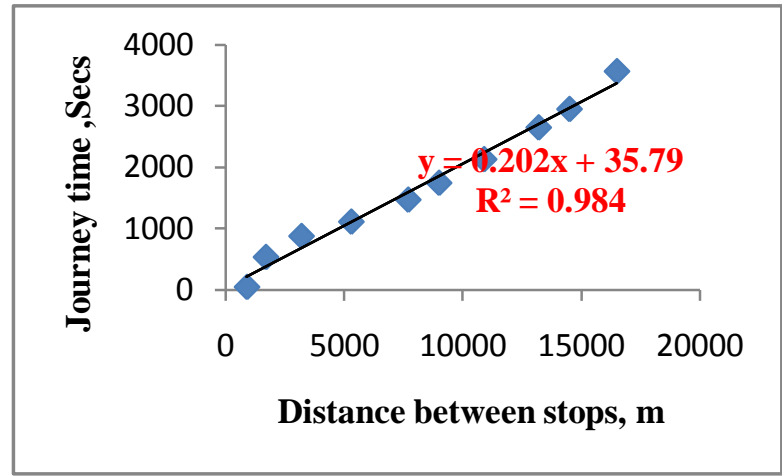

Figure 5: Plot of Journey time (sec) and between stops $\mathrm{m}$,

\subsection{Multiple Linear Regression Analysis:}

Multiple linear regression analysis is a well-known statistical technique for fitting mathematical relationships between dependent and independent variables. The multiple linear regression models express the mean of the response variable as a straight-line relationship of two or more predictor variables. The multiple regression analysis is done by using Statistica software.

\subsubsection{Stepwise Regression Analysis:}

Stepwise regression is a technique for choosing the variables to include in a regression model. Forward stepwise regression starts with no model terms. At each step it adds the most statistically significant term until there are none left. Backward stepwise regression starts with all the terms in the model and removes the least significant terms until all the remaining terms are statistically significant. It is also possible to start with a subset of all the terms and then add significant terms or remove insignificant terms. An important assumption behind the method is that some input variables in a multiple regression do not have an important explanatory effect on the response. The first step in stepwise regression technique is to determine the coefficients of determination for each predictor variable with the dependent variable. Models are given in Table 3.

Table 3: Stepwise Regression Models for Journey Time

\begin{tabular}{|c|c|c|}
\hline S1 No. & $\begin{array}{c}\text { Models for Journey Time } \\
\text { developed by Step wise regression }\end{array}$ & $\mathrm{R}^{2}$ Value \\
\hline 1. & $\mathrm{Y}=35.79+0.992 \mathrm{X}_{4}$ & 0.984 \\
\hline 2. & $\mathrm{Y}=593.767+1.07 \mathrm{X}_{4}+0.12 \mathrm{X}_{1}$ & 0.996 \\
\hline 3. & $\mathrm{Y}=471.737+1.04 \mathrm{X}_{4}+0.1 \mathrm{X}_{1}+0.04 \mathrm{X}_{3}$ & 0.994 \\
\hline
\end{tabular}

The final Multiple linear regression equation obtained was

$$
Y=490.25+0.0998 X_{1}+0.0085 X_{2}+0.0426 X_{3}+1.0444 X_{4}
$$

with Coefficient of Correlation $\mathrm{R}^{2}$ was 0.92 .

Where, $Y=$ Journey time (seconds), $\mathrm{X}_{1}=$ delay due to $\mathrm{B} \& \mathrm{~A}$ (seconds), $\mathrm{X}_{2}=$ delay due to issuing of tickets (seconds), $\mathrm{X}_{3}=$ delays due to other causes (seconds) and length of the stretch (m).

\subsection{Analysis of Modal Split:}

Since two Modes (passenger Cars and Public Transport) are available at present and Metro Rail likely to start service in near future, for the modal split analysis Multinominal Logit Model (MNL) has been used and is given by

$$
P_{m}=\frac{e^{w_{m n}}}{\sum_{m} e^{w_{m}}}
$$

Where,

$\mathrm{P}_{\mathrm{m}}=$ probability that mode $\mathrm{m}$ is chosen, $\mathrm{e}=$ base of natural logarithms and $\mathrm{m}=$ index over all modes included in the choice set.

\subsection{Utility Function:}

Utility function expresses the consumer's indifference between various alternative choices or attributes of these choices. The generalized Utility equation is given by

$$
\mathbf{U}=\boldsymbol{\beta}_{\mathbf{m}}-\boldsymbol{\alpha}_{\mathbf{1}} \mathbf{C}-\boldsymbol{\alpha}_{\mathbf{2}} \mathbf{T}
$$

Where, $\beta_{\mathrm{m}}=$ calibrated mode specific constant, $\alpha_{1}$ and $\alpha_{2}$ are constants, $\mathrm{C}=$ Out of pocket costs and $\mathrm{T}=$ Travel Time, Min Utility function is derived for the study stretch is given by: 


$$
\mathrm{U}=\beta \mathrm{m}-0.00696 \mathrm{C}-0.000285 \mathrm{~T}
$$

The above function of utility has been used to compute the Modal Split

From the study it has been found that, 6000 persons trip per day was performed along the selected corridor. For travelling between Kempegowda Bus Station to Yelahanka Town, the details of cost of the trip by individual modes and time of travel by individual modes are given in Table 4.

Table 4: Cost and travel time of individual modes

\begin{tabular}{|c|c|c|}
\hline Modes & $\begin{array}{c}\text { Cost of the Trip Indian } \\
\text { Rupee, (Rs) }\end{array}$ & $\begin{array}{c}\text { Travel time } \\
\text { mins }\end{array}$ \\
\hline Car & 90 & 40 \\
\hline Bus & 15 & 65 \\
\hline Metro Rail & 20 & 35 \\
\hline
\end{tabular}

Using the Multinomial Logit Model and Utility function ( the relationship 1 and 2) the number of trips generated by each mode ie calculated and tabulated in table. 5 .

Table 5: Probability of Choice and Number of trips by each mode

\begin{tabular}{|c|c|c|}
\hline Modes & $\begin{array}{l}\text { Probability of Choice } \\
\text { of mode }\end{array}$ & $\begin{array}{c}\text { Number of trips by } \\
\text { each mode }\end{array}$ \\
\hline Car & 0.126 & 720 \\
\hline Bus & 0.34 & 2040 \\
\hline Metro Rail & 0.54 & 3240 \\
\hline & Total & 6000 \\
\hline
\end{tabular}

From the Table 5 it can be seen that Car mode which is having a probability of $0.126(12.6 \%)$ will produce 720 trips, bus mode having a probability of $0.34(34 \%)$ will produce 2040 trips and Mass transit (metro) having a highest probability of $0.54(54 \%)$ will produce 3240 trips out of 6000 trips respectively.

Hence the Metro transit has the highest probability of usage which could produce more trips compared to other two modes.

\section{DISCUSSIONS AND CONCLUSIONS}

Based on the analysis and discussions of the data obtained in the selected route from Kempegowda Bus Station to Yelahanka Satellite Town the following conclusions are drawn

i). From the total journey time analysis components of total delay, delay due to boarding and alighting was influencing on the total journey time moderately.

ii). Other delay component delay due to issue of tickets affects the total journey time to a higher extent.

iii). The length of the route is the most influencing factor on the journey time.

iv). Regression models performed for attributes with journey time. It is found that delay due to boarding and alighting, delay due to issue of tickets and length of the route are significant by F-test at 10 percent level of confidence.

Based on the analysis and discussions of the Modal split, the following conclusions are drawn

i). Modal shift analysis shows Metro carries maximum number of trips compared to mono rail and private cars and hence Metro is an highly viable choice of mode for Bangalore Metropolitan Transport.

\section{REFERENCES}

[1] http://en.wikipedia.org/wiki/Talk:Bangalore

[2] Simha N R N, Veeraraghavan and R Sathyamurthy , "Optimisation of Bus Route Network of Bangalore City-A Case Study", Bangalore. IRC, Vol 12, 1992

[3] Ohba, Y., Koyama, T., and Shimada, S., "Online learning type of traveling time prediction model in expressway." IEEE Conf. on Intelligent Transp. Systems, Boston, 1997.

[4] Lelitha Devi Vanajakshi , "Estimation and Prediction of travel time from loop detector data for intelligent transportation systems", University of Kerala, India. 2004

\section{Thesis:}

[5] Van Lint J.W.C, "Reliable Travel Time Prediction for Freeways”, Trail Thesis Series no. T2004/3, The Netherlands TRAIL Research School Netherlands.2004

[6] RITES , "Comprehensive Traffic and Transportation Plan for Bangalore (CTTP) Bangalore Transportation: Research and Reports", Bangalore., 2007.

\section{Reports:}

[8] Land Transport Authority (LTA), "Passenger Transport Mode Shares in World Cities", Singapore.2011.

[9] KSIIDC-IL\&FS Project Development Company (KIPDC), "Pre Feasibility Report (draft) for Development of Intermodal Transit hub on PPP format at Yelahanka to Infrastructure Development Department”, Bangalore,2010

[10] Mukti Advani and Geetam Tiwari, “Evaluation of Public Transport Systems: Case Study of Delhi Metro”, START-2005, Indian Institute of Technology, Khargpur , India ,2005.

Books:

[11] Tom V. Mathew and Krishna Rao K V , “Introduction to Transportation Engineering”, IIT Bombay-2006

[12] James H.Banks, "Introduction To Transportation Engineering”, Second Edition Tata McGraw-HILL Publishers-2010. 